\title{
Description of a Unique Solitary Feeding Strategy Observed in Bottlenose Dolphins (Tursiops truncatus) in the Biloxi Marsh, Louisiana
}

\author{
Mystera M. Samuelson ${ }^{1,2, *}$, Ashley Millan Ambert ${ }^{1,3}$, Cristina Díaz Clark ${ }^{1}$, and Moby Solangi ${ }^{1}$ \\ ${ }^{1}$ The Institute for Marine Mammal Studies, Gulfport, MS \\ ${ }^{2}$ Department of Comparative Medicine, University of Nebraska Medical Center, Omaha, NE \\ ${ }^{3}$ Volusia County Environmental Management, DeLand, FL \\ *Corresponding author (Email: mystera.samuelson@unmc.edu)
}

Citation - Samuelson, M. M., Millan Ambert, A., Díaz Clark, C., \& Solangi, M. (2020). Description of a unique solitary feeding strategy observed in bottlenose dolphins (Tursiops truncatus) in the Biloxi Marsh, Louisiana. Animal Behavior and Cognition, 7(4), 505-513. doi: https://doi.org/10.26451/abc.07.04.03.2020

\begin{abstract}
Bottlenose dolphins' (Tursiops truncatus) foraging strategies in the Biloxi Marsh have received little attention when compared with other comparable habitats in the southeastern United States. Previous reports of dolphin foraging in this region have included sophisticated strategies such as strand feeding but have not included a detailed analysis of the observed behavior. Dolphins were observed performing a unique solitary foraging strategy, termed marsh bank feeding. Although this behavior was observed to occasionally result in stranding upon the marsh bank, it is argued here that the observed behavior is fundamentally different than the definitions for strand feeding, as well as other prominent shallow water foraging strategies. Video footage resulting from observations made between 2013 and 2019 were analyzed in order to establish the components of the behavior, enabling a detailed comparison to other dolphin foraging strategies.
\end{abstract}

Keywords - Bottlenose dolphin, Tursiops truncatus, Biloxi marsh, Foraging, Feeding strategies

The numerous and variable feeding strategies of bottlenose dolphins (Tursiops truncatus) are a distinguishing credit to their adaptive nature (Würsig, 1986), which allows this species to thrive in a wide variety of ecosystems, including marsh environments (Silber \& Fertl, 1995). Marshes are notably different than other dolphin habitats due to their shallow, turbid waters, muddy substrates, and outcroppings of cordgrass (Spartina spp.) creating steep embankments along the meandering channels (Hoese, 1971; Leatherwood, 1975; Orson, et al., 1985).

Feeding styles known to occur exclusively in marsh or shoreline habitats include circle feeding (Rigley et al., 1981), crowding (Leatherwood, 1975), shallow water feeding (Rigley et al., 1981), strand feeding (Hoese, 1971) and sweeping (Leatherwood, 1975). Although similar in delivery and context, these behaviors are unique and possess their own social and cognitive implications, due to their cooperative nature and the relative risk involved in their execution.

Shallow water feeding is characterized by tail-slapping by a solitary dolphin, while swimming parallel to a mud bank. The mud plume produced by this tail-slapping behavior acts as a visual barrier for prey, enabling the dolphin(s) to trap a group of fish between themselves and the shore. Alternately, the organized and cooperative circle feeding behavior is characterized by the trapping of prey within vortices and mud plumes produced by one or more animals rapidly swimming in a circle, trapping the prey inside. 
Both shallow water feeding and circle feeding are known to occur year-round and predominantly at low tide, when mud flats are exposed (Rigley et al., 1981). Sweeping and crowding are characterized as cooperative herding behaviors, which are usually performed by several individuals working together, with the intention of driving a school of fish toward shallow water, and have been observed in the region (Leatherwood, 1975). Similarly, barrier feeding has been described as the cooperative driving of fish toward a 'barrier' of other dolphins that trap the fish (Gazda et al., 2005). The term 'barrier feeding' has similarly been used to describe the herding of fish toward sea walls, bridge pilings, and other impediments against which prey can be trapped (Weiss, 2006; Würsig, 1986).

Beach feeding has been described as the "intentional beaching to capture fish chased onto shore" and has been observed along sand beaches and muddy marsh banks on the eastern coast of the United States. It excludes the use of a dolphin-induced bow wave to move prey fish onto a bank, as was reported in strand feeding, and specifies the dolphins' intention to beach, but also is not qualified as an exclusive group behavior (Silber \& Fertl, 1995).

Strand feeding, alternately, is characterized by the cooperative herding of fish toward a sloped mud bank, causing the fish to beach on the bank where the dolphins can then consume the trapped prey after partially or fully stranding themselves (Fox \& Young, 2012; Hoese, 1971). This behavior occurs in a well-studied four step process: 1) The dolphins locate a school of fish; 2) In unison, the dolphins assume a lineal formation parallel to shore; 3 ) In one quick motion, the dolphins charge the shoreline creating a bow wave and beaching on the marsh bank; 4) Once on the shore, the dolphins consume what fish they can and re-enter the water (Hoese, 1971). This cooperative and purposeful beaching behavior has both social and cognitive implications indicating that dolphins not only possess the ability to plan their behaviors, but also to communicate with group members enabling the coordination of the behavior. Additionally, this complex and risky behavior demonstrates the observational learning capabilities of young dolphins, who are thought to observe adults performing the behavior many times before ever attempting it on their own (Highfill \& Kuczaj, 2010). Strand feeding is observed year-round and exclusively during low tide events (Hoese, 1971; Rigley et al., 1981; Silber \& Fertl, 1995). Strand feeding has been reportedly observed in the Louisiana marshes (Natalia Botero Acosta, Briana Harvey, \& Shauna McBride, personal communication; Leatherwood, 1975), but these occurrences have not been evaluated in detail for comparison with accounts from other regions.

The present study began in order to examine dolphin behavior and population dynamics in the Biloxi Marsh in 2012 through the use of boat-based photo-ID surveys. During this time, researchers have observed various feeding behaviors in both shallow water and the deeper dredged channels. In this paper we describe a unique solitary feeding style, heretofore referred to as marsh bank feeding (MBF), observed in the Biloxi Marsh, Louisiana. This is the first detailed evaluation and description of this feeding style in the Biloxi Marsh, demonstrating additional behavioral plasticity and adaptability of dolphins in the Louisiana marshes. We also describe how this behavior differs from previously described shore-based feeding styles and those behaviors described by Leatherwood (1975).

\section{METHOD}

\section{Study Site}

The Biloxi Marsh is a 51,893 hectare brackish and intermediate coastal wetland located southeast of New Orleans in St. Bernard Parish, Louisiana (Figure 1; Lopez, 2005) and home to active brown (Farfantepenaeus aztecus) and white shrimp (Litopenaeus setiferus), oyster (Crassostrea virginica), and blue crab (Crassostrea virginica) harvesting industries. Dolphins in this region are known to feed on spotted sea trout (Cynoscion nebulosus; Wicker et al., 1982), mullet (Mugil sp.; Scott et al., 1990), croaker (Micropogonias undulates; Mead \& Potter, 1990, as cited in Gannon \& Waples, 2004), red drum (Sciaenops ocellatus; Baltz et al., 1993), and menhaden (Brevoortia patronus; Barros \& Wells, 1998; Leatherwood, 1975). 
Figure 1

Location of the Biloxi Marsh and Observed Marsh Bank Feeding Locations

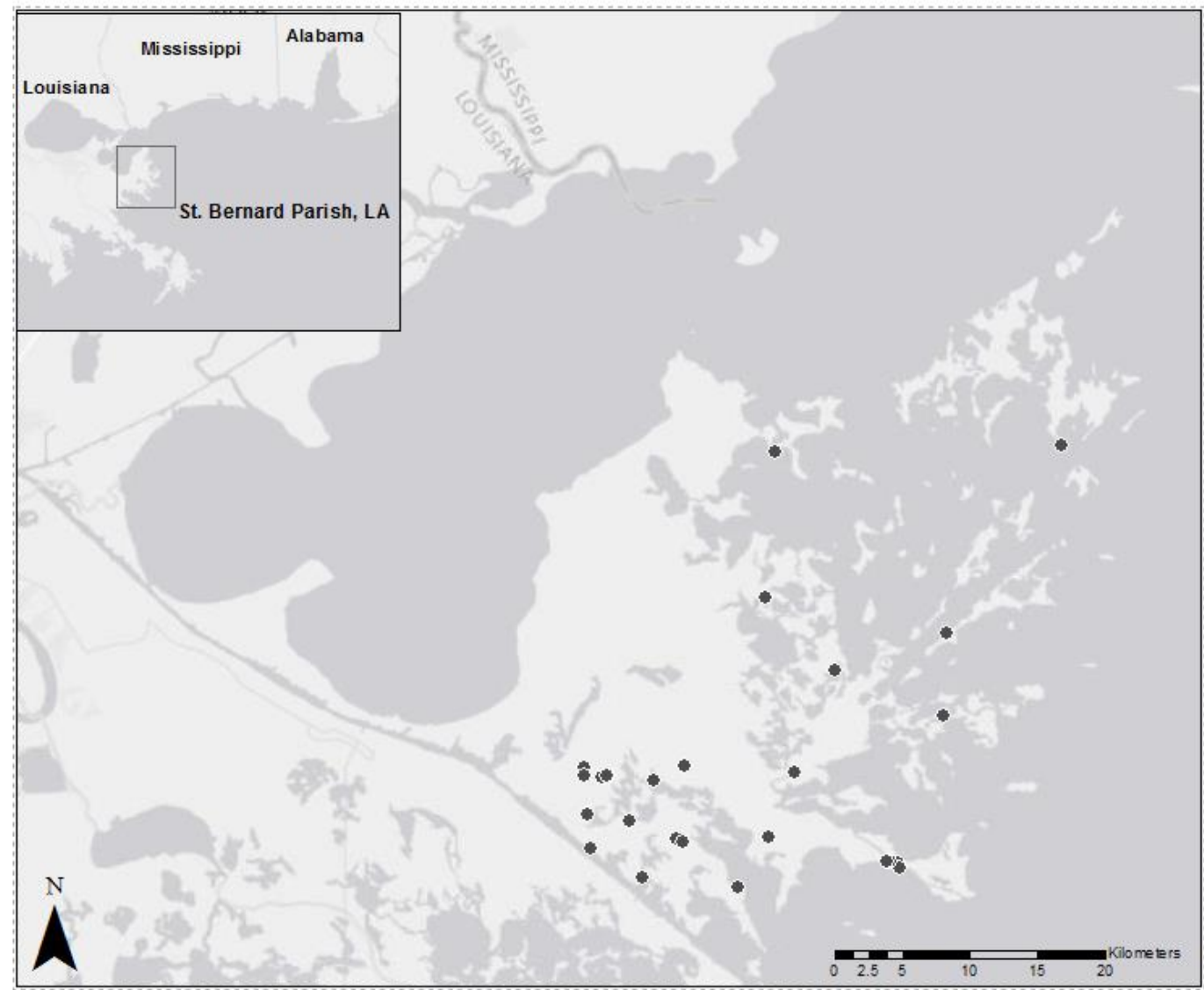

\section{Data Collection}

The Institute for Marine Mammal Studies (IMMS) in Gulfport, Mississippi, has conducted monthly boat-based photo-ID surveys in the Biloxi Marsh since 2012. The research team logged 551.15 hrs surveying the Biloxi Marsh between 2012 and 2019, sighting approximately 3,690 dolphins (including 2,874 adults, 816 juveniles, and 92 neonates). The survey platform was a $7 \mathrm{~m}$ vessel powered by a $250 \mathrm{hp}$ outboard engine and travelling at a maximum speed of $40 \mathrm{~km} / \mathrm{h}$ while on survey, resulting in an observer level of $0.9 \mathrm{~m}$ above sea level. During sightings the boat speed was reduced to match the pace of the dolphins being observed. Sightings lasted no longer than 30 min (as per permits GA LOC \#13549, $\# 18185$, and \#22081). A minimum of four observers searched for dolphins, photographed individual dorsal fins, recorded feeding behaviors, and took down sighting notation. Group size, composition, and behavioral states were documented in addition to weather and environmental conditions such as sea state, depth, and water quality (temperature, $\mathrm{pH}$, salinity, and dissolved oxygen). Sighting locations were recorded using a handheld Garmin GPSmap76 global positioning system (GPS) equipped with depth finder, and photographs of individual dorsal fins in each group were taken using Canon EOS 50D, 60D, and 70D digital cameras with a Canon 400-mm zoom lens respectively. Video recordings were taken using a Panasonic HDC-SD40P/PC and later a Canon VIXIA HF G40. 


\section{Data Analysis}

From 2013 to 2019, MBF was observed during 27 sightings by IMMS staff. Of these, 13 sightings were recorded on video. The resulting footage was evaluated by independent coders, using an ethogram (Table 1). Inter-rater reliability was evaluated to ensure consistency of data coding, exceeding $90 \%$ consistency in coding.

\section{Table 1}

Operational Definitions Used for Video Coding of Behaviors

\section{Operational Definitions for Behaviors}

\begin{tabular}{|c|c|}
\hline Pair Swim & $\begin{array}{l}\text { Two animals swim in unison with one another, within one body length of one another (Yeater \& Kuczaj, } \\
2010 .\end{array}$ \\
\hline Group Swim & $\begin{array}{l}\text { Three or more animals swim together in unison, within one body length of one another (Yeater \& Kuczaj, } \\
\text { 2010). }\end{array}$ \\
\hline Solo Swim & $\begin{array}{l}\text { The dolphin surfaces alone, other nearby dolphins are at least one full body length away }(4.5 \mathrm{~m} \text { ), are not } \\
\text { swimming in synchrony with the observed dolphin (Miller et al., 2010), and are more than two body } \\
\text { lengths away from shore. }\end{array}$ \\
\hline
\end{tabular}

Foraging Dolphin swimming parallel with shore. Direction of movement varies; the individual performs short dives, often arching its back at the surface to increase forward motion speed. Category includes circling and hard stops. (Adapted from Hazelkorn et al., 2016; Bowen, 2011).

Pinwheeling A sudden maneuver in which the dolphin rolls its body $\sim 90^{\circ}$ and rapidly flexes its body ventrally, producing a turn around the axis of the location of the dolphin's rostrum (Maresh et al., 2004).

Hard Stop Dolphin swimming about $\sim 1 \mathrm{~m}$ from shore at slow speed, then raising its caudal peduncle out of the water while keeping its fluke underwater. Motion causes an immediate stop in the forward movement of the dolphin (Bowen, 2011).

Chase A rapid burst of speed followed by apparent persistent pursuit of prey; observed in dolphins swimming in normal orientation or side swim. Usually involving unpredictable quick movements (Miller et al., 2010).

Probable Feed Characterized by dolphin splashing or performing erratic movements of the head, usually following a lunge, chase, or beaching event; as well as fish seen jumping ahead of dolphin.

Feed Dolphin is engaged in behaviors directed toward the attainment of prey, such as, repeated fluke in/fluke out dives in one location, feeding circles, lunge feeds, fish kicks, fish tosses, and/or a fish seen in mouth (Miller et al., 2010).

Fluke Slap The dolphin's fluke makes contact with the surface of the water, usually smacking the surface with its fluke (Miller et al., 2010).

Kerplunk Dolphin lifts flukes out of the water and then thrusts flukes down quickly to impact water surface, the fluke impact creates a small initial splash at $\sim 45^{\circ}$ angle, followed by a large vertical splash $(1-3.5 \mathrm{~m})$. The behavior produces an audible "kerplunk" sound (Connor et al., 2000; Nowacek, 1999).

Fluke out Dive

The dolphin surfaces and then dives down under the water raising its fluke up in the air and out of the water (Miller et al., 2010).

Fluke in Dive

The dolphin surfaces and then dives down under the water with the fluke remaining below the surface of the water (Miller et al., 2010).

Spyhop The dolphin moves in such a way that the upper part of the body rises above the water in a vertical position (Miller et al., 2010).

Note. Coders also recorded distance to shore in body length, orientation to shore, speed, stranding, and the amount of the dolphins' body that stranded. 


\section{Results}

Behavioral coding confirmed that the MBF behavior occurred in four distinct stages: 1) An individual dolphin swam slowly parallel to and within less than one body length, or 2.5-3 m (Bearzi et al., 1997) from the marsh bank (Figure 2a); 2) When the animal identified a target prey item, an individual fish chase was initiated (Figure 2b, 2c \& 2d); 3) The dolphin then herded a single fish toward the marsh bank (Figure 2e) in an attempt to capture the prey (Figure 2f). If successful, the behavior concluded in catching the prey as it was trapped against the marsh bank. If unsuccessful, the behavior concluded in a reset, in which the animal began patrolling for fish again (stage 1).

To evaluate the behavior, coders separated the foraging into occurrences. A single occurrence was defined as having completed steps one through three of the described behavior. That is, if an animal completed the described behavior, stages 1-3, this was considered one occurrence. If the animal then began swimming slowly along the shoreline (stage 1), this was considered a new occurrence.

\section{Figure 2}

Marsh Bank Feeding Behavioral Sequence
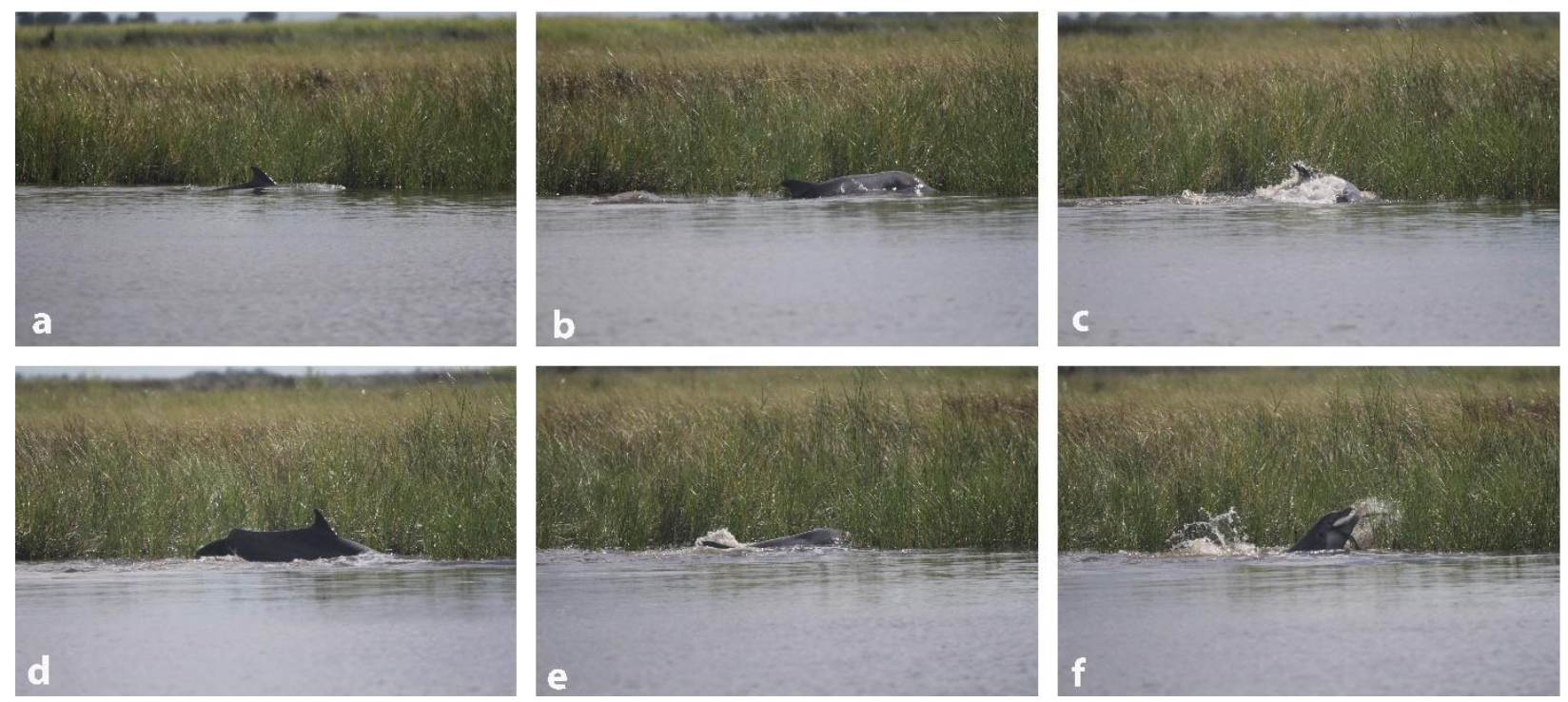

Note. a) Dolphin swims parallel to shore, b) dolphin increases speed and angles its body toward shore, c) dolphin lunges toward shore d) the animal continues fish chase into shallow water, e) the individual herds fish against the marsh bank, f) successful capture of a speckled sea trout.

Due to the opaque nature of the water in the Biloxi Marsh, a successful fish catch was inferred by the rapid shaking of the individual's head paired with a slowing in the swimming speed of the individual, indicating the completion of the fish chase. Following a successful, or unsuccessful, fish chase, the dolphin typically resumed the aforementioned slow swim pattern parallel to the marsh bank, indicating a return to foraging. Behavioral coding identified $137 \mathrm{MBF}$ occurrences, which were observed during 13 filmed sightings. However, it should be noted that this is a low estimate as the behavior was observed during 14 additional sightings, which were not filmed and thus not included in this count.

While this behavior does occasionally $(n=137)$ result in the dolphins' partial $(\leq 0.5$ body length $)$ or full ( $>0.5$ body length) stranding $(n=8)$ on the marsh bank, occasional beaching events appeared to be a coincidental result of a spirited fish chase, rather than a part of the overall foraging strategy. Strandings were performed individually, as with the other behaviors, and did not involve the bow wave that is typically associated with strand feeding (i.e., Hoese, 1971; Rigley et al., 1981; Silber \& Fertl, 1995). Furthermore, individuals did not strand consistently nor were specific individuals more likely to strand than other individuals observed, again suggesting the stranding event itself was likely the consequence of 
the individual's pursuit of an individual prey item. When fish were observed by researchers, it was noted that dolphins were pursuing a single large fish (i.e., spotted sea trout) rather than a school of fish. Dolphins did not strand on their lateral side, as has been observed in strand feeding (Hoese, 1971), but rather stranded on their ventral side on every stranding occasion, including both partial and full.

Although MBF is a solitary behavior, individuals were frequently observed performing this behavior while within 0.25-0.5 miles of other group members. When in the presence of other group members, the other dolphins typically engaged in other feeding strategies such as open water feeding within the deeper waters of the canal. Group sizes ranged from 1-17 individuals at a time during MBF observations, resulting in a total of 71 individual dolphins (56 adults, 15 juveniles) observed to be present in groups exhibiting MBF. However, of these 71 individuals, only $48 \%$ of these animals were observed engaging in the MBF behavior $(n=34)$. Despite the large group size during some MBF sightings, no more than 5 individuals were observed performing the MBF behavior during the same sighting. When two or more individuals were observed performing the behavior within the same sighting, they moved independently of one another, performing all three steps of the behavior individually. Furthermore, they neither reacted to, nor elicited a reaction from, other dolphins foraging in the same area regardless of chosen strategy. Only adults participated in the MBF behavior. Of those observed, $11 \%(n=8)$ were known animals, and had been observed in and around the Biloxi Marsh on prior photo-ID surveys. When engaged in simultaneous MBF, group members did not cooperate (i.e., perform the behavior in unison or parallel each other's behavior to herd fish toward shore or toward one another). Social behaviors such as pair swimming or tactile behavior were not observed before, during, or following MBF events. Moreover, individuals appeared to disperse during the foraging event. The distance between animals varied during foraging events; however, animals did not travel together or in any otherwise coordinated fashion during foraging events. Dolphins accompanying individuals who were engaged in MBF were likewise engaged in feeding behaviors, although not the same strategy (i.e., feeding in the open water of the channel).

MBF events were observed equally as often at high $(48 \%, n=13)$ and low $(52 \%, n=14)$ tide, and during all four seasons. For the purposes of this study, high and low tide was defined by the NOAA Tides and Currents Prediction Tool (www.tidesandcurrents.noaa.gov/). The Biloxi Marsh is characterized by only one high and low tide event per 24-hour period. While the majority of encounters occurred in dredged channels ranging in depth from $0.39-19.23 \mathrm{~m}$ (average $=3.23 \mathrm{~m}$ ), dolphins frequently continued this behavior as they travelled down shallow channels branching off of the main waterway. While this concluded the sighting, as the boat was unable to follow the dolphins in this shallow water, it is likely to occur outside of the regularly observed area.

Due to the high turbidity of the water in the Biloxi Marsh, the sought-after prey species were often difficult to identify despite the observers' close range. However, when identified, the individuals were observed feeding on spotted sea trout, redfish (Sciaenops ocellatus), and mullet.

\section{Discussion}

Leatherwood (1975) reported observations of crowding, sweeping and some reports of strand feeding in bottlenose dolphins, which are known to be learned cooperative behaviors. However, the data presented here demonstrates that bottlenose dolphins in the Biloxi Marsh rather employ a non-cooperative crowding-like behavior in which individual fish are systematically identified and herded toward a steep embankment to aid in their capture. Strandings in pursuit of the fish do not appear to represent a significant proportion of these sequences and are quite likely the unintended consequences of a spirited fish chase. Of particular note, is that even when multiple animals (up to five individuals) engaged in the marsh bank feeding strategy simultaneously, they did not interact with other marsh bank feeders, regardless of proximity.

During cooperative strand feeding events, dolphins typically strand on their lateral side rather than ventral (Hoese, 1971; Rigley et al., 1981; Silber \& Fertl, 1995). The side an individual chooses to strand upon is biased toward the right lateral side and has even been hypothesized to indicate a left hemispheric dominance in dolphins (Karenina et al., 2016). The consistent nature of this behavior during 
these feeding events suggest that the behavior is intentional. In the Biloxi Marsh, however, individuals were consistently observed stranding on their ventral side and only partially stranded $(50 \%$ of the body length or less). These observed individuals beached inconsistently, and when stranding, did so with no discernable pattern. This suggests that the beaching component of the behavior was not only unplanned, but possibly unintended despite planning being involved in the execution of the overall behavior.

MBF does resemble the previously described barrier feeding in many ways. However, barrier feeding has been defined as being cooperative in nature (Gazda et al., 2005) as well as horizontally transmitted (Weiss, 2006), whereas the MBF behavior was observed to be a solitary behavior at all points and did not involve calves or juveniles. Additionally, dolphins in the Biloxi Marsh were not observed employing this strategy with other barriers such as oyster reefs despite the abundance of such barriers in the marsh. This suggests that there may be some unique benefit to employing the marsh bank as a barrier.

Of individuals observed employing this strategy, eight were re-sighted in and near the Biloxi Marsh by the IMMS photo-ID project. These known individuals engaged in the described feeding strategy on at least two encounters and were both observed travelling with a group as well as independently. Due to the opaque nature of the water in the Biloxi Marsh, and the manner in which dolphins tend to beach when pursuing fish during MBF events (in ventral recumbency), we were unable to determine sex for any of the observed animals.

The low rate of re-sighting is likely due to the difficulty of sampling within the marsh habitat, as well as the fact that the surveyed location is located within a stock-mixing area. That is, it is likely that extended surveys to the west of the Biloxi Marsh, and within the Chandeleur Sound, or comparisons with photo-identification databases obtained in these areas would be yield a higher re-sight rate.

While juveniles were present for MBF events, they were not observed to engage in the behavior alongside adults. Instead, they were observed milling and/or feeding in the deeper waters of the channel with other group members. This is similar to observations of strand feeding groups in other areas and has been hypothesized to indicate a horizontal transmission of this behavior, obtained through observational learning (Highfill \& Kuczaj, 2010). However, to determine this, additional research involving extended observations greater than 30 minutes in length (as allowed by the current observer permits) would likely be needed.

This lack of a methodical stranding technique, the occurrence of strandings at both high and low tide, as well as the lack of cooperation between group members demonstrates a marked difference between MBF, strand feeding (Hoese, 1971), and crowding (Leatherwood, 1975). Findings from this study differ from previous descriptions of strand feeding that had been observed in this population. Of those individuals who were re-sighted two or more times, individuals observed in the Biloxi Marsh have a re-sight rate of over $80 \%$ within the marshes with some limited re-sighting in the southern portion of Lake Borgne - particularly near Le Petit Pass. Dolphins sighted in the Biloxi Marsh were rarely observed in the greater Mississippi Sound (Samuelson et al., in press), indicating site fidelity within the marsh habitat. Thus, it is unsurprising that several of these individuals have been sighted performing this behavior in the marsh on previous occasions. However, the marshes are inherently difficult to survey due to their winding channels and the shallow nature of the marsh, making it difficult to sight and follow dolphins in many areas by boat. This is a limitation of boat-based surveys in marsh habitats. Future research would benefit from the use of unmanned aerial vehicles (UAV) deployed from the survey platform, thereby reducing this limitation. This method of observation has been previously used by researchers to study dolphin behavior and feeding strategies (Fettermann de Oliveira, 2018; Nowacek et al., 2001, 2016). The employment of UAV for behavioral observation would prove invaluable in capturing behavioral data and increase our current understanding of feeding strategies used by the dolphin population in the Biloxi March. 


\section{Acknowledgements}

We would like to thank the staff and interns who assisted in data collection, including Trevor Jensen who assisted with an earlier iteration of this project. Research was conducted under NOAA, National Marine Fisheries Service Permits GA LOC \#13549, \#18185, and \#22081. We also like to thank the IMMS for funding these research efforts.

\section{References}

Baltz, D. M., Rakocinski, C., \& Fleeger, J. W. (1993). Microhabitat use by marsh-edge fishes in a Louisiana estuary. Environmental Biology of Fishes, 36, 109-126.

Barros, N. B., \& Wells, R. S. (1998). Prey and feeding patterns of resident bottlenose dolphins (Tursiops truncatus) in Sarasota Bay, Florida. Journal of Mammalogy, 79, 1045-1059.

Bearzi, G., Notarbartolo di Sciara, G., \& Politi, E. (1997). Social ecology of bottlenose dolphins in the Kvarnerić (northern Adriatic Sea). Marine Mammal Science, 13, 650-668.

Bowen, S. R. (2011). Diet of bottlenose dolphins Tursiops truncatus in the northwest panhandle and foraging behavior near Savannah, Georgia [unpublished doctoral dissertation]. Savannah State University.

Connor, R. C., Wells, R. S., Mann, J., \& Read, A. J. (2000). The bottlenose dolphin. In J. Mann, R. C. Connor, P. L. Tyack, \& H. Whitehead (Eds.) Cetacean societies: Field studies of dolphins and whales (pp. 91-125). University of Chicago Press.

Fettermann de Oliveira, T. (2018). Unmanned aerial vehicle (UAV) remote sensing of behaviour and habitat use of the nationally endangered bottlenose dolphin (Tursiops truncatus) off Great Barrier Island (unpublished doctoral dissertation]. Auckland University of Technology.

Fox, A. G., \& Young, R. F. (2012). Foraging interactions between wading birds and strand-feeding bottlenose dolphins (Tursiops truncatus) in a coastal salt marsh. Canadian Journal of Zoology, 90, 744-752.

Gannon, D. P., \& Waples, D. M. (2004). Diets of coastal bottlenose dolphins from the US mid-Atlantic coast differ by habitat. Marine Mammal Science, 20, 527-545.

Gazda, S. K., Connor, R. C., Edgar, R. K., \& Cox, F. (2005). A division of labour with role specialization in grouphunting bottlenose dolphins (Tursiops truncatus) off Cedar Key, Florida. Proceedings of the Royal Society B: Biological Sciences, 272, 135-140.

Hazelkorn, R. A., Schulte, B. A., \& Cox, T. M. (2016). Persistent effects of begging on common bottlenose dolphin (Tursiops truncatus) behavior in an estuarine population. Aquatic Mammals, 42, 531-541.

Highfill, L. E., \& Kuczaj, S. A. II. (2010). How studies of wild and captive dolphins contribute to our understanding of individual differences and personality. International Journal of Comparative Psychology, 23, $269-277$.

Hoese, H. D. (1971). Dolphin feeding out of water in a salt marsh. Journal of Mammalogy, 52, $222-223$.

Karenina, K., Giljov, A., Ivkovich, T., \& Malashichev, Y. (2016). Evidence for the perceptual origin of right-sided feeding biases in cetaceans. Animal Cognition, 19, 239-243.

Leatherwood, S. (1975). Some observations of feeding behavior of bottle-nosed dolphins (Tursiops truncatus) in the northern Gulf of Mexico and (Tursiops cf T. gilli) off Southern California, Baja California, and Nayarit, Mexico. Marine Fisheries Review, 37, 10-16.

Lopez, J. A. (2005). The multiple lines of defense strategy to sustain Louisiana's coast. Journal of Coastal Research, 54, 186-197.

Maresh, J. L., Fish, F. E., \& Nowacek, D. P. (2004) High performance turning capabilities during foraging by bottlenose dolphins. Marine Mammal Science, 20, 498-509.

Mead, J. G., \& Potter, C. W. (1990). Natural history of bottlenose dolphins along the central Atlantic coast of the United States. In S. Leatherwood \& R. R. Reeves (Eds.), The bottlenose dolphin (pp. 165-195). Academic Press.

Miller, L. J., Solangi, M., \& Kuczaj, S. A. (2010). Seasonal and diurnal patterns of behavior exhibited by Atlantic bottlenose dolphins (Tursiops truncatus) in the Mississippi Sound. Ethology, 116, 1127-1137.

Nowacek, D. P. (1999). Sound use, sequential behavior and ecology of foraging bottlenose dolphins, Tursiops truncatus (No. MIT/WHOI-99-16). Woods Hole Oceanographic Institution, MA.

Nowacek, D. P., Tyack, P. L., \& Wells, R. S. (2001). A platform for continuous behavioral and acoustic observation of free-ranging marine mammals: Overhead video combined with underwater audio. Marine Mammal Science, 17, 191-199. 
Nowacek, D. P., Christiansen, F., Bejder, L., Goldbogen, J. A., \& Friedlaender, A. S. (2016). Studying cetacean behaviour: New technological approaches and conservation applications. Animal Behaviour, 120, 235-244.

Orson, R., Panageotou, W., \& Leatherman, S. P. (1985). Response of tidal salt marshes of the US Atlantic and Gulf coasts to rising sea levels. Journal of Coastal Research, 1, 29-37.

Rigley, L., Vandyke. G. V., Cram, P., \& Rigley, I. (1981). Shallow water behavior of the Atlantic bottlenose dolphin (Tursiops truncatus). Proceedings of the Pennsylvania Academy of Science 55, 157-159.

Samuelson, M. M., Fujiwara, M., Pulis, E. E., Pitchford, J. L., Howard, V., \& Solangi, M. (in press). A comprehensive evaluation of survival and population growth estimates for Tursiops truncatus (Common bottlenose dolphins) in the Mississippi Sound, USA, following the Deepwater Horizon oil spill. Southeastern Naturalist.

Scott, M. D., Wells, R. S., \& Irvine, A. B. (1990). A long-term study of bottlenose dolphins on the west coast of Florida. In S. Leatherwood \& R. R. Reeves (Eds.), The bottlenose dolphin (pp. 235--244). Academic Press.

Silber, G. K., \& Fertl, D. (1995). Intentional beaching by bottlenose dolphins (Tursiops truncatus) in the Colorado River Delta, Mexico. Aquatic Mammals, 21, 183-186.

Weiss, J. (2006). Foraging habitats and associated preferential foraging specializations of bottlenose dolphin (Tursiops truncatus) mother-calf pairs. Aquatic Mammals, 31, 10-19.

Wicker, K. M., Castille, G. C., Davis, D. J., Gagliano, S. M., Roberts, D. W., Sabins, D. S., \& Weinstein, R. A. (1982). St. Bernard Parish: A study in wetland management. Coastal Environments, Inc., Baton Rouge, LA. Contract \# 168-909 132 p.

Würsig, B. (1986). Delphinid foraging strategies. In R. J. Schusterman, J. A. Thomas, \& F. G. Wood (Eds.), Dolphin cognition and behavior: A comparative approach (pp. 347-359). Lawrence Erlbaum Associates.

Yeater, D. B., \& Kuczaj, S. A. (2010). Observational learning in wild and captive dolphins. International Journal of Comparative Psychology, 23, 379-385. 